\title{
Analisis Peran Stakeholder Terhadap Kesuksesan Proyek Konstruksi
}

\author{
'Zainuddin ${ }^{2}$ Aulia \\ 1,2 Program Studi Teknik Sipil, Fakultas Teknik, Universitas Muhammadiyah Aceh \\ 1zainuddin@unmuha.ac.id \\ 2awib.aulia@gmail.com
}

\begin{abstract}
Good management of the project is a prerequisite for achieving project objectives. Every construction company must be able to demonstrate the quality of its services so that it can excel in the competition. The problem in this study is whether the role of stakeholders affects the success of a construction project and how much influence it has on the success of the project. In this study the sample taken was the Department of Housing and Settlements of Banda Aceh City and obtained 6 respondents and PT Coplanar Daya Maxima obtained 4 respondents. Respondents in the purpose of this study were to find out what roles and how much influence stakeholders have on the success of construction projects. Data collection technique is distributing questionnaires to respondents. Data processing was carried out using validity and reliability tests then data analysis using descriptive analysis and product moment correlation, as well as multiple linear regression using SPSS version 25 . This study consisted of independent variables $(X)$ consisting of owners $(X 1)$, employees $(X 2)$, suppliers $(X 3)$, consumers $(X 4)$, competitors $(X 5)$ and business licenses $(X 6)$ and the selection variable $(Y)$. The test results for the validity of the r-table value of 0.6319 meet the requirements for $r$-count $>r$-table. The results of the reliability test show that all independent variables $(X)$ and stakeholder determinant variables $(Y)$ are reliable. This is because it has met the minimum coefficient of Cronbach Alpha, which is greater than 0.6. The results of descriptive analysis have the lowest mean value found in the employee variable (X2) and business license (X6) of 4.100 and the highest mean value of the supplier variable (X3) of 4.475 which shows that the average respondent's answer is important, then all variables play an important role in project success. construction. The results of multiple linear regression obtained the following equation: $Y=24.018+0.412 X 1-0.002 X 2-0.759 X 3-0.526 X 4+0.427 X 5$ $-0.701 X 6$. The analysis shows that the dominant influence of the role of stakeholders on the success of the project is in the supplier variable (X3) with a regression coefficient value of -0.759 and the level of relationship between suppliers (X3) and stakeholders. The results of the classification of the relationship level on the value of the correlation coefficient based on the interval table of the correlation coefficient value and the strength of the relationship.
\end{abstract}

Keywords: Stakeholders, Activities, Construction Projects

\section{ABSTRAK}

Pengelolaan yang baik dari proyek merupakan syarat tercapainya tujuan proyek, Setiap perusahaan konstruksi dituntut agar mampu menunjukkan kualitas pelayanannya sehingga bisa unggul dalam persaingan. Permasalahan dalam penelitian ini apakah peran stakeholder mempengaruhi kesuksesan proyek konstruksi dan seberapa besar pengaruhnya terhadap kesuksesan proyek tersebut. Dalam penelitian ini sampel yang diambil adalah Dinas Perumahan dan Permukiman Kota Banda Aceh dan didapat responden sebanyak 6 orang serta PT Coplanar Daya Maxima didapat responden sebanyak 4 orang. Responden pada tujuan penelitian ini adalah untuk mengetahui peran apa saja dan seberapa besar tingkat yang mempengaruhi stakeholderterhadap kesuksesan proyek konstruksi. Teknik pengumpulan data adalah membagikan kuisioner kepada responden. Pengolahan data dilakukan menggunakan uji validitas dan uji reliabilitas kemudian data di analisis menggunakan analisa deskriptif dan korelasi product moment, serta regresi linier berganda menggunakan program SPSS versi 25. Penelitian ini terdiri dari variabel bebas $(X)$ yang terdiri dari pemilik (X1), karyawan (X2), supplier (X3), konsumen $(X 4)$, pesaing $(X 5)$ dan izin usaha $(X 6)$ serta variabel terikat $(Y)$. Hasil uji validitas nilai r-tabel 0,6319 memenuhi syarat $r$-hitung $>$ r-tabel. Hasil uji reliabilitas menunjukkan bahwa semua variabel bebas $(\mathrm{X})$ dan variabel terikat stakeholder $(\mathrm{Y})$ adalah reliabel. Hal ini dikarenakan telah memenuhi koefisien minimum Cronbach Alpha yaitu lebih besar dari 0,6. Hasil analisis deskriptif nilai mean terendah terdapat pada variabel karyawan $(X 2)$ dan izin usaha $(X 6)$ sebesar 4,100 serta nilai mean tertinggi pada variabel supplier (X3) sebesar 4,475 yang menunjukkan rata-rata jawaban responden penting, maka semua variabel berperan penting terhadap kesuksesan proyek konstruksi. Hasil regresi linier berganda diperoleh persamaan yaitu: $Y=24.018+$ $0.412 \mathrm{X} 1-0.002 \mathrm{X} 2-0.759 \mathrm{X} 3-0.526 \mathrm{X} 4+0.427 \mathrm{X} 5-0.701 \mathrm{X} 6$. Analisis menunjukkan bahwa pengaruh dominan dari peran stakeholder terhadap kesuksesan proyek berada pada variabel supplier (X3) dengan nilai koefisien regresi sebesar -0.759 dan tingkat hubungan yang sedang antara variabel supplier (X3) terhadap stakeholder. Hasil klasifikasi tingkat hubungan pada nilai koefisien korelasi berdasarkan pada tabel interval nilai koefisien korelasi dan kekuatan hubungan.

Kata kunci : Stakeholder, Kesuksesan, Proyek Konstruksi 


\section{Pendahuluan}

Proyek konstruksi saat ini menghadapi banyak tantangan ketika memasuki era globalisasi. Sebuah proyek dikatakan berhasil jika pembangunan diselesaikan tepat waktu, sesuai anggaran dan kualitas baik. Selain itu juga memberikan kepuasan yang tinggi pada pelanggan. Masing-masing proyek memiliki sekumpulan tujuan untuk dicapai dan menggunakan tujuan tersebut sebagai standar untuk mengukur kinerja. Pengelolaan yang baik dari suatu proyek merupakan syarat tercapainya tujuan proyek. Harapan stakeholder atas kinerja perusahaan adalah proyek diselesaikan secara tepat waktu dan tepat mutu. Tidak sedikit permasalahan yang terdapat dalam suatu proyek menyebabkan terlambatnya jadwal proyek, biaya proyek meningkat, kerugian proyek bahkan kualitas proyek yang menurun dapat terjadi bila pengelolaan proyek kurang baik.

Di tengah semakin ketatnya persaingan dalam dunia bisnis konstruksi ini, setiap perusahaan konstruksi dituntut agar mampu menunjukkan kualitas pelayanannya sehingga bisa unggul dalam persaingan. Dalam pelayanannya, kinerja perusahaan dihadapkan pada permasalahan yang berhubungan dengan tingkat kepuasan stakeholder. Bila kinerja perusahaan dapat memenuhi harapan maka stakeholder akan puas dan demikian pula sebaliknya. Keberhasilan dalam penentuan kebijakan dan dukungan terhadap penyelesaian suatu masalah tertentu akan sangat tergantung kepada stakeholder yang dipilih untuk diprioritaskan. Dampak yang terjadi dari pemangku kepentingan sangat mempengaruhi proses konstruksi dalam menghasilkan sebuah kesuksesan, di mana makin besar kekuatan yang dimiliki pemangku kepentingan, makin besar pula pengaruhnya terhadap keberhasilan proyek.

Berkenaan dengan permasalahan tersebut, tujuan penelitian ini adalah untuk mengetahui peran apa saja yang mempengaruhi serta seberapa besar tingkat pengaruh peran stakeholder terhadap kesuksesan proyek konstruksi. Penelitian ini dilakukan di Kota Banda Aceh dengan responden yang akan dituju adalah Dinas Perumahan Rakyat Dan Kawasan Permukiman Kota Banda Aceh serta PT Coplanar Daya Maxima. Penelitian ini dilakukan dengan membagikan kuesioner serta dengan kriteria pertanyaan dari pemilik, karyawan, supplier, konsumen, pesaing, izin usaha dan stakeholder. Pengolahan data dilakukan menggunakan uji validitas dan uji reliabilitas, kemudian data analisis menggunakan analisa deskriptif dan korelasi Product Moment, serta regresi berganda mengunakan Software Statistical Product and Service Solution (SPSS) Versi 25.

Berdasarkan hasil analisa korelasi nilai koefisien interval variabel pemilik, karyawan, konsumen, pesaing dan izin usaha memiliki tingkat hubungan yang sangat rendah dengan nilai koefisien sebesar $0.059 ;-0.150 ;-0.102 ; 0.167 ; 0.075$. Hal ini berarti bahwa variabel pemilik, karyawan, konsumen, pesaing dan izin usaha memiliki signifikan hubungan yang sangat rendah dengan stakeholder. Sedangkan pada variabel supplier memiliki tingat hubungan sedang dengan nilai koefisien sebesar -0.488 . Hasil klasifikasi tingkat hubungan pada nilai koefisien korelasi berdasarkan pada tabel interval nilai koefisien korelasi dan kekuatan hubungan.

\section{Tinjauan Pustaka}

\subsection{Stakeholder}

Seluruh stakeholder mempunyai hak untuk disediakan informasi tentang bagaimana kegiatan organisasi memengaruhi mereka, bahkan mereka memilih untuk tidak menggunakan informasi tersebut dan bahkan ketika mereka tidak bisa secara langsung melakukan peran konstruktif dalam kelangsungan hidup organisasi [17].

Perusahaan bukanlah identitas yang hanya beroperasi untuk kepentingannya sendiri, namun harus memberikan manfaat bagi stakeholder (pemegang saham, kreditor, konsumen, supplier, pemerintah, masyarakat, analis dan pihak lain) [6].

\subsection{Keberhasilan Proyek}

Beberapa faktor yang mempengaruhi keberhasilan suatu proyek adalah:

1. Biaya

[1] berpendapat setiap proyek tergantung pada biaya atau anggaran. Banyak peneliti menilai biaya sebagai kriteria keberhasilan yang sangat penting, di mana perencanaan anggaran biaya dan estimasi biaya yang tepat telah disebutkan sebagai faktor keberhasilan.

2. Kualitas/mutu

Kualitas adalah produk atau proses, telah 
dianggap baik sebagai kriteria keberhasilan proyek dan faktor oleh berbagai peneliti [7].

3. Waktu

[3] berpendapat lebih dari setengah dari 30 referensi menunjukkan waktu sebagai salah satu kriteria keberhasilan proyek yang paling penting untuk setiap proyek.

\subsection{Populasi dan Sampel}

Populasi adalah wilayah generalisasi yang terdiri dari atas obyek atau subyek yang mempunyai kualitas dan karakteristik tertentu yang ditetapkan oleh peneliti untuk dipelajari dan kemudian ditarik kesimpulannya. Sampel adalah bagian dari jumlah dan karakteristik yang dimiliki oleh populasi tersebut [16]. Semakin besar sampel dari besarnya populasi yang ada adalah semakin baik, akan tetapi ada jumlah batas minimal yang harus diambil oleh peneliti yaitu sebanyak 10 sampel [4].

\subsection{Teknik Sampling}

Teknik sampling merupakan teknik pengambilan sampel [16]. Untuk menentukan sampel dalam penelitian, terdapat berbagai teknik sampling yang digunakan.

1. Probability sampling, adalah teknik pengambilan sampel yang memberikan peluang yang sama bagi setiap unsur (anggota) populasi untuk dipilih menjadi anggota sampel.

2. Nonprobability sampling, adalah teknik pengambilan sampel yang tidak memberi peluang/kesempatan sama bagi setiap unsur atau anggota populasi untuk dipilih menjadi sampel.

\subsection{Pengolahan Data Statistik}

Pada prinsipnya statistik diartikan sebagai kegiatan untuk mengumpulkan data, meringkas atau menyajikan data, menganalisa data dengan metode tertentu dan menginterpretasikan hasil analisis tersebut [11].

- Uji validitas yang menggunakan rumus:

$$
R x y=\frac{n(\Sigma x y)-(\Sigma x)(\Sigma y)}{\sqrt{\left\{n \Sigma x^{2}-(\Sigma x)^{2}\right\}\left\{n \Sigma y^{2}-(\Sigma y)^{2}\right\}}}
$$

Keterangan:

$\mathrm{Rxy}=$ Menunjukkan indeks korelasi antara dua variabel yang dikorelasikan

$\mathrm{R}=$ Koefisien validitas item yang dicari, dua variabel yang dikorelasikan
$\mathrm{X}=$ Skor untuk pernyataan yang dipilih

$Y=$ Skor total yang diperoleh dari seluruh item

$\Sigma \mathrm{x}=$ Jumlah skor dalam distribusi $\mathrm{X}$

$\Sigma \mathrm{y}=$ Jumlah skor dalam distribusi $\mathrm{X}$

$\Sigma x^{2}=$ Jumlah kuadrat dalam skor dalam distribusi $X$

$\Sigma \mathrm{y}^{2}=$ Jumlah kuadrat dalam skor dalam distribusi $Y$

$\mathrm{N}$ = Banyaknya responden

- Uji reliabilitas yang menggunakan rumus:

$r i=\left[\frac{k}{k-1}\right]\left[1-\frac{\Sigma \sigma b^{2}}{\sigma t^{2}}\right]$

Keterangan:

$\mathrm{ri}=$ Reliabilitas instrumen

$\mathrm{k}=$ Banyaknya butir pertanyaan

$2 \sum \sigma b=$ Jumlah varian butir

$2 \sigma \mathrm{t}=$ Varians total

- Analisis deskriptif menggunakan rumus:

$\mathrm{P}=\frac{\mathrm{F}}{\mathrm{N}} \times 100 \%$

Keterangan:

$\mathrm{P}=$ Persentase jawaban

$F=$ Frekuensi nilai yang diperoleh dari seluruh ítem

$\mathrm{N}$ = Jumlah responden

- Analisis korelasi product moment menggunakan rumus:

$R x y=\frac{\sum x y}{\sqrt{\sum x^{2} y^{2}}}$

Keterangan:

rxy $=$ Korelasi antara variabel $x$ dengan $y$

$\mathrm{x}=(\mathrm{xi}-\mathrm{x})$

$y=(y i-y)$

- Analisis regresi berganda menggunakan rumus:

$Y=a+b_{1} X_{1}+b_{2} X_{2}+b_{3} X_{3}+\varepsilon$

Keterangan:

$\mathrm{Y}=$ Variabel dependen

$\mathrm{X} 1, \mathrm{X} 2, \mathrm{X} 3=$ Variabel independen

$\alpha=$ Konstanta

b1, b2, b3 = Koefisien regresi

$\varepsilon=$ Eror (variabel gagal)

\subsection{Kuesioner}

Kuesioner merupakan alat pengumpulan data primer dengan metode survei untuk memperoleh opini responden [9]. Kuesioner dapat didistribusikan kepada responden dengan cara: (1) Langsung oleh peneliti (mandiri); (2) Dikirim lewat pos (mailquestionair); (3) Dikirim lewat komputer misalnya surat elektronik (e-mail). Peneliti juga harus merancang bentuk kuesionernya, yaitu pertanyaan yang sifatnya terbuka atau tertutup. Pertanyaan terbuka memungkinkan responden menjawab bebas dan seluas-luasnya terhadap 
pertanyaan namun dalam pertanyaan tertutup, responden hanya diberi kesempatan memilih jawaban yang tersedia.

\subsection{Skala Likert}

Skala likert digunakan untuk mengukur sikap, pendapat, dan persepsi seseorang atau kelompok tentang kejadian atau gejala sosial [10]. Variabel yang akan diukur dijabarkan menjadi indikator variabel. Kemudian indikator tersebut dijadikan sebagai titik tolak untuk menyusun item-item instrument yang berupa pernyataan.

Tabel 1. Katagori jawaban variabel

\begin{tabular}{ccc}
\hline No. & Kualifikasi & Skor \\
\hline 1 & Sangat Tidak Penting (STP) & 1 \\
2 & Tidah Penting (TP) & 2 \\
3 & Kurang Penting (KP) & 3 \\
4 & Pentings (P) & 4 \\
5 & Sangat Penting (SP) & 5 \\
\hline
\end{tabular}

Sumber: Riduwan (2014)

\section{Metode Penelitian}

\subsection{Objek dan Lokasi Penelitian}

Objek penelitian ini adalah pada perusahaan pekerjaan proyek konstruksi PT Coplanar Daya Maxima yang berlokasi di Jl. Melur Lr. Seuruni Blok B No. 10 Kampung Lamteh, Kecamatan Ulee Kareng, Kota Banda Aceh dan Dinas Perumahan Rakyat Dan Kawasan Permukiman Kota Banda Aceh JIn. Imam Bonjol No. 1 Kampung Baru, Kecamatan Baiturrahman, Banda Aceh.

\subsection{Proses Pengumpulan Data}

Pengumpulan data ini mencakup pengumpulan data primer dan pengumpulan data sekunder yang dapat dijelaskan pada penjelasan berikut :

\subsubsection{Data primer}

Data primer adalah data yang diperoleh peneliti secara langsung dari sumbernya. Data primer yang digunakan dalam penelitian adalah data kuesioner. Menyiapkan seperangkat pertanyaan untuk ditujukan kepada responden. 1. Mencari informasi mengenai waktu yang tepat untuk melakukan penyebaran kuesioner.

2. Menyebarkan dan mengumpulkan kuesioner penelitian ke lokasi sesuai dengan waktu yang sudah direncanakan.

\subsubsection{Data sekunder}

Proses pengumpulan data sekunder berupa peta Provinsi Aceh dan peta Kota Banda Aceh.

\subsection{Menentukan Populasi dan Sampel}

Populasi merupakan keseluruhan individu atau kelompok yang akan diteliti sedangkan sampel adalah bagian kecil dari populasi yang dipilih berdasarkan prosedur tertentu yang akan mewakili populasinya. Populasi dalam penelitian ini adalah stakeholder pada kesuksesan proyek konstruksi yang berada di Kota Banda Aceh sedangkan untuk sampel diambil dari populasi yang dianggap representatif dengan metode pengambilan sampel yang digunakan dalam penelitian ini adalah nonprobability sampling dengan teknik sampling kuota.

Tabel 2. Populasi dan jumlah responden

\begin{tabular}{clc}
\hline No & \multicolumn{1}{c}{ Populasi } & Jumlah \\
\hline 1 & Dinas Perumahan & \\
& Rakyat Dan Kawasan & \\
& Permukiman Kota & 6 \\
& Banda Aceh & \\
$2 \quad$ & PT Coplanar Daya \\
& Maxima & 4 \\
& Total & 10 \\
\hline
\end{tabular}

\subsection{Variabel Penelitian}

Variabel Penelitian adalah hal-hal yang menjadi objek penelitian yang diamati dalam suatu kegiatan penelitian. Variabel dalam penelitian ini terdiri dari variabel bebas $(X)$ dan variabel terikat $(Y)$. Variabel-variabel tersebut antara lain: $\mathrm{X}_{1}=$ Pemilik, $\mathrm{X}_{2}=$ Karyawan, $\mathrm{X}_{3}=$ Supplier, $\mathrm{X}_{4}=$ Konsumen, $\mathrm{X}_{5}=$ Pesaing, $\mathrm{X}_{6}=$ Izin usaha dan $\mathrm{Y}=$ Stakeholder.

Pengumpulan data kuesioner dilakukan dengan cara menjumpai langsung setiap responden, responden diminta untuk memilih langsug jawaban yang telah disediakan dengan 
memberikan checklist $(\sqrt{ })$.

Skala pengukuran yang digunakan dalam penelitian ini adalah skala likers. Setiap jawaban dari responden nantinya dapat diungkapkan dari penilaian sangat penting sampai sangat tidak penting, dengan nilai skor mulai dari 1 sampai 5 .

Tabel 3. Indikator variabel penelitian

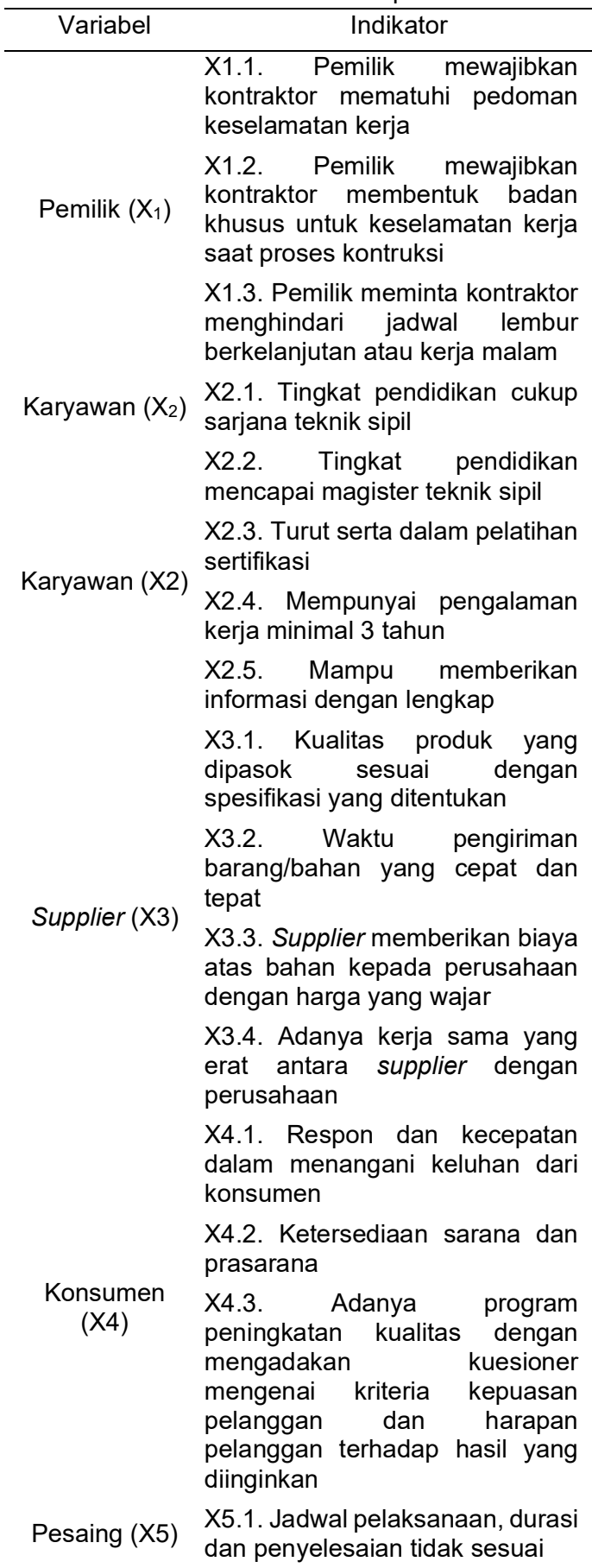

X5.2. Kurangnya kepemilikan sarana

X5.3. Perusahaan menyediakan produk dengan kualitas tinggi

X6.1. Perusahaan melakukan persiapan izin usaha sebelum mengikuti tender

Izin Usaha

X6.2. Tenaga ahli yang dipakai adalah tenaga ahli yang bersertifikat yaitu memiliki SKA dan SKT

Kesuksesan Y1.1. Fasilitas yang diberikan Proyek

Konstruksi (Y) Y2.2. Kerja sama

\subsection{Teknik Pengolahan Sampel}

Pengolahan data ini merupakan bagian uji instrumen penelitian dengan menggunakan metode statistik melalui uji validitas dan uji reliabilitas.

\subsubsection{Uji validitas}

Uji validitas ini dilakukan untuk mengetahui valid atau tidak validnya suatu pernyataan dalam kuesioner berdasarkan data isian yang diterima dari responden.

1. Setiap butir pertanyaan yang terdapat dalam kuesioner dilakukan uji validitas melalui bantuan program SPSS.

2. Output yang dihasilkan dari uji validitas melalui program tersebut merupakan nilai Rhitung, yang selanjutnya dibandingkan dengan nilai Rtabel.

3. Bila nilai Rhitung > Rtabel maka maka pernyataan dalam kuesioner yang diisi oleh stakeholder akan valid, sedangkan bila nilai yang diperoleh Rhitung < Rtabel, maka pernyataan dalam kuisioner yang diisi oleh stakeholder tidak valid.

\subsubsection{Uji reliabilitas}

Uji reliabilitas ini dilakukan untuk mengetahui reliabel atau tidak reliabelnya suatu variabel pada kuesioner yang digunakan berdasarkan data isian yang diterima dari responden.

1. Setiap variabel yang terdapat dalam kuesioner dilakukan uji reliabilitas melalui bantuan program SPSS.

2. Output yang dihasilkan dari persamaan tersebut merupakan nilai Cronbach Alpha. yang selanjutnya dibandingkan dengan nilai 
0,6 sebagai nilai ketetapan.

3. Bila nilai Cronbach Alpha pada variabel diperoleh $>0,6$, maka kuesioner yang telah diisi oleh kontraktor akan reliabel, sedangkan bila nilai Cronbach Alpha yang diperoleh < 0,6 maka kuisioner yang telah diisi oleh responden tidak reliabel.

4. Bila suatu variabel tidak reliabel, maka langkah yang dilakukan adalah dengan menggunakan analisis faktor untuk merotasi kembali faktor, dan setelah semua variabel sudah reliabel, maka barulah dilanjutkan pada tahap analisa data.

\subsection{Analisis Data}

Setelah uji valitidas dan reliabilitas selesai pada proses pengolahan data, instrumen yang digunakan selanjutnya dalam penelitian ini adalah yang telah memenuhi kriteria valid dan reliabel. Analisa data ini menggunakan metode statistik yaitu analisis deskriptif dan analisis korelasi yang akan dibantu dengan menggunakan software SPSS versi 25.

\subsubsection{Analisis deskriptif}

Analisis deskriptif digunakan untuk mengetahui karakteristik responden.

1. Butir-butir pertanyaan pada kuesioner bagian A dilakukan analisis deskriptif melalui bantuan software SPSS

2. Output yang dihasilkan dari software tersebut yaitu frekuensi dan persentase karakteristik responden mulai dari jenis kelamin, umur, pendidikan terakhir dan jabatan.

\subsubsection{Analisis korelasi product moment}

Analisis korelasi digunakan untuk melihat hubungan antara variabel X1, X2, X3, X4, X5, X6 dengan variabel Y. Uji Pearson Moment adalah salah satu dari beberapa jenis uji korelasi yang digunakan untuk mengetahui derajat keeratan hubungan 2 variabel yang berskala interval atau rasio, di mana dengan uji ini akan mengembalikan nilai koefisien korelasi yang nilainya berkisar antara $-1,0$ dan 1 . Nilai 1 artinya terdapat korelasi negatif yang sempurna, 0 artinya tidak ada korelasi dan nilai 1 berarti ada korelasi positif yang sempurna.

1. Setiap variabel yang terdapat dalam kuesioner dilakukan analisis korelasi melalui bantuan program SPSS.

2. Output yang dihasilkan dari persamaan tersebut merupakan nilai koefisien korelasi antara variabel.

3. Nilai koefisien korelasi tersebut selanjutnya dilihat bentuk keeratan hubungannya. Dalam hal ini keeratan hubungannya dapat dinyatakan dalam bentuk seperti tidak ada hubungan sama sekali, sangat rendah, cukup, tinggi, dan sempurna sesuai dengan nilai koefisien yang diperoleh.

\subsubsection{Analisis regresi berganda}

Metode analisis regresi berganda dilakukan untuk menguji pengaruh dua atau lebih variabel independen terhadap variabel dependen.

1. Membentuk pola hubungan antara variabel dependen dan independen.

2. Mencari variabel mana yang sesungguhnya signifikan menjelaskan variasi dari variabel independen.

3. Variabel independen mana yang sesungguhnya berpengaruh terhadap variabel dependen.

\section{Hasil dan Pembahasan}

\subsection{Uji Validitas}

Uji validitas digunakan untuk mengetahui pernyataan pada kuesioner valid atau tidak, berdasarkan data isian yang diterima dari responden. Pertanyaan dinyatakan valid jika nilai $R_{\text {-hitung }}>\mathrm{R}_{\text {-tabel }}$ atau nilai $\mathrm{p}$-value lebih kecil dari alpha $5 \%$.

Tabel 4. Hasil uji validitas

\begin{tabular}{|c|c|c|c|c|}
\hline Aspek & No & $\begin{array}{c}\text { Correlate } \\
d \text { Total } \\
\text { Corelation }\end{array}$ & $\begin{array}{c}\text { R-table } \\
\text { Nilai } \\
\text { Kritis 5\% }\end{array}$ & Keterangan \\
\hline & $\mathrm{X} 1$ & 0.893 & 0,6319 & Valid \\
\hline Pemilik (X1) & $X 2$ & 0.807 & 0,6319 & Valid \\
\hline \multirow{7}{*}{$\begin{array}{l}\text { Kehadiran } \\
\quad(\mathrm{X} 2)\end{array}$} & X3 & 0.733 & 0,6319 & Valid \\
\hline & $\mathrm{X} 1$ & 0.746 & 0,6319 & Valid \\
\hline & $\mathrm{X} 2$ & 0.714 & 0,6319 & Valid \\
\hline & X3 & 0.640 & 0,6319 & Valid \\
\hline & $X 4$ & 0.714 & 0,6319 & Valid \\
\hline & $\times 5$ & 0.706 & 0,6319 & Valid \\
\hline & $\mathrm{X} 1$ & 0.793 & 0,6319 & Valid \\
\hline
\end{tabular}




\begin{tabular}{|c|c|c|c|c|}
\hline \multirow{3}{*}{$\begin{array}{l}\text { Supplier } \\
\text { (X3) }\end{array}$} & $\mathrm{X} 2$ & 0.921 & 0,6319 & Valid \\
\hline & X3 & 0.797 & 0,6319 & Valid \\
\hline & $X 4$ & 0.821 & 0,6319 & Valid \\
\hline \multirow{3}{*}{$\begin{array}{c}\text { Konsumen } \\
(\mathrm{X} 4)\end{array}$} & $\mathrm{X} 1$ & 0.806 & 0,6319 & Valid \\
\hline & $\mathrm{X} 2$ & 0.722 & 0,6319 & Valid \\
\hline & X3 & 0.964 & 0,6319 & Valid \\
\hline \multirow{3}{*}{$\begin{array}{l}\text { Pesaing } \\
\text { (X5) }\end{array}$} & $\mathrm{X} 1$ & 0.963 & 0,6319 & Valid \\
\hline & $\mathrm{X} 2$ & 0.791 & 0,6319 & Valid \\
\hline & X3 & 0.745 & 0,6319 & Valid \\
\hline \multirow{2}{*}{$\begin{array}{l}\text { Izin Usaha } \\
\quad(X 6)\end{array}$} & $\mathrm{X} 1$ & 0.84 & 0,6319 & Valid \\
\hline & $\mathrm{X} 2$ & 0.889 & 0,6319 & Valid \\
\hline $\begin{array}{c}\text { Kesuksesan } \\
\text { Proyek }\end{array}$ & X1 & 0.873 & 0,6319 & Valid \\
\hline $\begin{array}{l}\text { Konstruksi } \\
(\mathrm{Y})\end{array}$ & $x 2$ & 0.873 & 0,6319 & Valid \\
\hline
\end{tabular}

Tabel 4 memperlihatkan jumlah responden yang digunakan berjumlah 10 orang responden. Sehingga tabel $\mathrm{R}$ Pearson yang digunakan $(\mathrm{N}=10-2=8)$ yaitu bernilai sebesar 0,6319. Sehingga, berdasarkan hasil uji validitas kuesioner diketahui bahwa semua pertanyaan valid, hal ini dikarenakan nilai koefisien korelasi total setiap item pertanyaan pervariabel lebih besar dari nilai $\mathrm{R}$ tabel $(0,6319)$.

\subsection{Uji Reliabilitas}

Uji reliabilitas digunakan untuk mengetahui variabel pada kuesioner dapat dipercaya (reliable) atau tidak, berdasarkan data isian yang diterima dari responden.

Tabel 5. Uji reliabilitas

\begin{tabular}{ccccc}
\hline Variabel & $\begin{array}{c}\text { Juml } \\
\text { ah } \\
\text { Item }\end{array}$ & $\begin{array}{c}\text { Cronbach } \\
\text { Alpha }\end{array}$ & $\begin{array}{c}\text { Nilai Kritis } \\
\text { Cronbach } \\
\text { Alpha }\end{array}$ & Keterangan \\
\hline $\begin{array}{c}\text { Pemilik } \\
\text { (X1) }\end{array}$ & 3 & 0.732 & 0.6 & Reliabel \\
$\begin{array}{c}\text { Karyawan } \\
\text { (X2) }\end{array}$ & 5 & 0.736 & 0.6 & Reliabel \\
$\begin{array}{c}\text { Supplier } \\
\text { (X3) }\end{array}$ & 4 & 0.853 & 0.6 & Reliabel \\
$\begin{array}{c}\text { Konsume } \\
\text { n (X4) }\end{array}$ & 3 & 0.778 & 0.6 & Reliabel \\
$\begin{array}{c}\text { Pesaing } \\
(\text { X5) }\end{array}$ & 3 & 0.787 & 0.6 & Reliabel \\
$\begin{array}{l}\text { Izin } \\
\text { Usaha } \\
(\text { X6) }\end{array}$ & 2 & 0.659 & 0.6 & Reliabel \\
& & & &
\end{tabular}

\begin{tabular}{l}
$\begin{array}{c}\text { Kesukses } \\
\text { an Proyek } \\
\text { Konstruksi } \\
(\mathrm{Y})\end{array}$ \\
\hline
\end{tabular}

Tabel 5 memperlihatkan bahwa semua variabel pada kuesioner mempunyai nilai Cronbach Alpha > 0,6, sehingga variabelnya semua reliable.

\subsection{Analisis Deskriptif}

Data dari penelitian ini diperoleh dari penyebaran kuesioner pada responden pada adalah Dinas Perumahan Rakyat Dan Kawasan Permukiman Kota Banda Aceh. Pada subbab ini akan dilakukan analisa terhadap peran stakeholder terhadap proyek konstruksi dengan menggunakan analisa deskriptif. Deskripsi jawaban dilakukan dengan mengitung nilai ratarata, dan peringkat jawaban dari masingmasing indikator pertanyaan.

\section{Karakteristik Responden}

Pengumpulan data dalam penelitian ini dilakukan dengan menggunakan kuesioner yang disampaikan secara langsung kepada para responden, kualifikasi jabatan yang akan dijadikan responden adalah stakeholder pada Dinas Perumahan Rakyat Dan Kawasan Permukiman Kota Banda Aceh yang peneliti sebanyak 10 orang yaitu 6 orang dari Dinas Perumahan Rakyat Dan Kawasan Permukiman Kota Banda Aceh serta 4 orang dari PT Coplanar Daya Maxima. Berdasarkan output di atas diketahui bahwa frekuensi umur dari 10 responden yang paling dominan pada penelitian ini umur tertinggi berada diantara 4150 tahun sebesar 40 \%. Dari Gambar 2 dapat dilihat bahwa pada pendidikan responden, responden yang berpendidikan SI sebesar $80 \%$ dari total responden dan responden yang berpendidikan S2 sebesar $20 \%$ dari total responden. Berdasarkan output di atas diketahui bahwa dari frekuensi pendidikan terakhir dari 10 responden yang mendominasi penelitian ini berada pada berpendidikan S1 sebesar $80 \%$.

Dari Gambar 3 dapat dilihat bahwa, responden yang berdomisili di Banda Aceh sebesar $100 \%$ dari total responden. Artinya bahwa seluruh 
responden yang saya teliti berdomisili tempat tinggal di Banda Aceh tanpa ada yang berdomisili di luar Banda Aceh.

2. Persepsi responden pada stakeholder terhadap kesuksesan proyek konstruksi

Dalam penelitian ini, aspek yang diambil adalah pemilik, karyawan, supplier, konsumen, pesaing izin usaha dan kesuksesan proyek konstruksi. Dari variabel pemilik dijabarkan ke dalam 3 (Tiga) item pernyataan, aspek karyawan dijabarkan ke dalam 5 (Lima) item pernyataan, aspek supplier dijabarkan ke dalam 4 (Empat) item pernyataan, aspek konsumen dan pesaing dijabarkan ke dalam 3 (Tiga) item pernyataan, dan dari aspek izin usaha dan kesuksesan proyek konstruksi dijabarkan ke dalam 2 (Dua) item pernyataan. Masing-masing pernyataan pilihan jawaban sangat tidak penting (dengan skor 1) sampai dengan sangat penting (dengan skor 5).

Tabel 6. Rekapitulasi mean variabel bebas $(X)$

\begin{tabular}{cc}
\hline Variabel & MEAN \\
\hline Pemilik (X1) & 4.467 \\
Karyawan (X2) & 4.100 \\
Supplier (X3) & 4.475 \\
Konsumen (X4) & 4.400 \\
Pesaing (X5) & 4.200 \\
Izin Usaha (X6) & 4.100 \\
\hline
\end{tabular}

Dari tabel 6 diatas dapat dilihat dari responden variabel bebas Mean tertinggi terdapat pada variabel supplier (X3) yaitu sebesar 4,475.

\begin{tabular}{cc} 
Tabel 7. Rekapitulasi mean variabel terikat $(\mathrm{Y})$ \\
\hline Variabel & MEAN \\
\hline Fasilitas Yang Diberikan (Y1) & 4.400 \\
Kerja Sama (Y2) & 4.000 \\
\hline
\end{tabular}

Dari tabel 7 merupakan rekapitulasi jawaban dari variabel terikat $(Y)$ dengan mean tertinggi terdapat pada (Y.1) yaitu sebesar 4,400.

\subsection{Analisis Korelasi Product Moment}

Analisis korelasi merupakan teknik statistik yang digunakan untuk mengetahui derajat pengaruh antar variabel. Analisis korelasi bisa dilakukan dengan menggunakan analisis Korelasi Product Moment.

Tabel 8. Tingkat hubungan

\begin{tabular}{ccc}
\hline Variabel & $\mathrm{Y}$ & \multirow{2}{*}{ Tingkat Hubungan } \\
\cline { 2 - 3 } & Korelasi & \\
\hline Pemilik (X1) & 0.059 & Sangat Rendah \\
Karyawan (X2) & -0.150 & Sangat Rendah \\
Supplier (X3) & -0.488 & Sedang \\
Konsumen (X4) & -0.102 & Sangat Rendah \\
Pesaing (X5) & 0.167 & Sangat Rendah \\
Izin Usaha (X6) & 0.075 & Sangat Rendah \\
\hline
\end{tabular}

Dari tabel 8 diatas dapat dilihat bahwa variabel pemilik, karyawan, konsumen, pesaing dan izin usaha memiliki tingkat hubungan yang sangat rendah dengan nilai koefisien sebesar 0.059 ; $0.150 ;-0.102 ; 0.167 ; 0.075$. Hal ini berarti bahwa variabel memiliki signifikan hubungan yang sangat rendah dengan stakeholder. Sedangkan pada variabel supplier memiliki tingkat hubungan sedang dengan nilai koefisien sebesar -0.488 .

\subsection{Analisis Regresi Linier Berganda}

Analisis regresi berganda ini digunakan untuk mengetahui peran stakeholder terhadap kesuksesan proyek konstruksi dengan melihat koefisien regresi.

Tabel 9. Koefisien regresi linier berganda

\begin{tabular}{cc}
\hline Variabel & Koefisien Regresi \\
\hline Konstanta & 24.018 \\
Pemilik (X1) & 0.412 \\
Karyawan (X2) & -0.002 \\
Supplier (X3) & -0.759 \\
Konsumen (X4) & -0.526 \\
Pesaing (X5) & 0.427 \\
Izin Usaha (X6) & -0.701 \\
\hline
\end{tabular}

Untuk hasil output analisis regresi berganda melalui program SPSS dapat dilihat pada Lampiran B.4.16 halaman 61. Berdasarkan output SPSS table model summary, dapat dijelaskan bahwa angka $R$ square adalah 0,970 yang mana hanya $97,00 \%$ sedangkan sisanya sebesar $3,00 \%$ dijelaskan oleh faktor-faktor stakeholder yang lain yang tidak diteliti pada penelitian ini. 
1. Konstanta sebesar 24.018 yang memiliki arti jika variabel independen $(X)$ bernilai 0 , maka variabel dependen $(Y)$ akan dipengaruhi oleh variabel lain. Indentifikasi controlling ini secara matematis pengaruhnya diukur secara numerik sebesar 24.018.

2. Koefisien regresi variabel oleh indikator pendapatan (X1) sebesar 0.412 menyatakan bahwa setiap peningkatan perubahan pendapatan sebesar satu satuan maka stakeholder akan menurun sebesar 0.412 .

3. Koefisien regresi variabel oleh indikator kehadiran (X2) sebesar -0.002 menyatakan bahwa setiap peningkatan perubahan pendapatan sebesar satu satuan maka stakeholder akan mengalami perubahan atau akan meningkat sebesar -0.002 .

4. Koefisien regresi variabel oleh indikator kebutuhan sosial (X3) sebesar -0.759 menyatakan bahwa setiap peningkatan perubahan pendapatan sebesar satu satuan maka stakeholder akan mengalami perubahan atau akan meningkat sebesar 0.759 .

5. Koefisien regresi variabel oleh indikator motivasi kerja (X4) sebesar -0.526 menyatakan bahwa setiap peningkatan perubahan pendapatan sebesar satu satuan maka stakeholder akan menurun sebesar 0.526 .

6. Koefisien regresi variabel oleh indikator kebutuhan sosial (X5) sebesar 0.427 menyatakan bahwa setiap peningkatan perubahan pendapatan sebesar satu satuan maka stakeholder akan mengalami perubahan atau akan meningkat sebesar 0.427 .

7. Koefisien regresi variabel oleh indikator kebutuhan sosial (X6) sebesar -0.701 menyatakan bahwa setiap peningkatan perubahan pendapatan sebesar satu satuan maka stakeholder akan mengalami perubahan atau akan meningkat sebesar 0.701 .

\subsection{Pembahasan}

Analisis deskriptif menunjukkan bahwa nilai mean tertinggi terdapat pada terdapat pada variabel supplier (X3) yaitu sebesar 4,475 sedangkan nilai mean terendah terdapat pada variabel karyawan (X2) dan izin usaha (X6) dengan nilai mean sebesar 4,100

Dari hasil analisis korelasi menunjukkan bahwa peran stakeholder terhadap kesuksesan proyek konstruksi pada Dinas Perumahan Rakyat Dan Kawasan Permukiman Kota Banda Aceh berada pada variabel tertinggi yaitu supplier (X3) mempunyai hubungan yang sedang terhadap kesuksesan proyek konstruksi dengan nilai korelasinya sebesar -0.488 sedangkan nilai terendah terdapat pada variabel pemilik (X1) dengan nilai korelasinya sebesar 0.059 dan mempunyai hubungan sangat rendah terhadap kesuksesan proyek konstruksi.

Dari hasil analisis regresi berganda menunjukkan bahwa peran stakeholder terhadap kesuksesan proyek konstruksi pada Dinas Perumahan Rakyat Dan Kawasan Permukiman Kota Banda Aceh berada pada variabel supplier (X3) dengan nilai koefisien regresi tertinggi sebesar -0.759 terhadap kesuksesan proyek konstruksi.

\section{Kesimpulan}

\subsection{Kesimpulan}

Berdasarkan hasil perhitungan dan pembahasan mengenai peran stakeholder terhadap kesuksesan proyek konstruksi, maka berikut ini dapat diberikan beberapa kesimpulan dan saran:

1. Analisis deskriptif menunjukkan bahwa nilai mean tertinggi terdapat pada fasilitas yang diberikan dan kerja sama $(Y)$ dengan nilai mean masing-masing sebesar 4,400, sedangkan nilai mean terendah terdapat pada variabel karyawan (X2) dan izin usaha (X6) dengan nilai mean sebesar 4,100. Hal ini berarti bahwa rata-rata responden memberi tangggapan bahwa peran stakeholder terhadap kesuksesan proyek konstruksi setuju dalam semua aspek.

2. Analisis reliabilitas menunjukkan bahwa semua instrumen penelitian yang terdiri dari variabel bebas yaitu pemilik, karyawan, supplier, konsumen, pesaing, izin usaha dan variabel terikat yaitu stakeholder adalah valid. Hal ini dikarenakan telah memenuhi koefisien minimum Cronbach Alpha yaitu lebih besar dari 0,6.

3. Analisis regresi berganda diperoleh model regresi yaitu $Y=24.018+0.412 \mathrm{X} 1-$ 
$0.002 \times 2-0.759 \times 3-0.526 \times 4+0.427 \times 5-$ $0.701 \times 6$. Koefisien regresi terbesar terdapat pada variabel X3 sebesar -0.759 yaitu supplier. Dengan demikian variabel dominan dari peran stakeholder terhadap kesuksesan proyek konstruksi berada pada variabel supplier.

4. Dari hasil analisis menunjukkan bahwa variabel dominan dari peran stakeholder terhadap kesuksesan proyek konstruksi berada pada variabel supplier (X3) dengan nilai koefisien regresi sebesar -0.488 dan tingkat hubungan yang sedang antara variabel supplier (X3) terhadap kesuksesan proyek konstruksi.

\subsection{Saran}

Adapun saran yang peneliti berikan adalah sebagai berikut:

1. Penelitian ini hanya dilakukan di Kota Banda Aceh. Sebaiknya penelitian dilakukan pada lokasi selain Kota Banda Aceh, misalnya seluruh daerah yang ada di Provinsi Aceh, agar dapat memberi informasi mengenai peran stakeholder terhadap kesuksesan proyek konstruksi.

2. Bagi peneliti selanjutnya diharapkan dapat dikembangkan lebih lanjut lagi, sehingga dapat menambah dan memperkaya ilmu mengenai peran stakeholder terhadap kesuksesan proyek konstruksi.

3. Disarankan untuk peneliti selanjutnya dalam menyelesaikan metode statistik ini dapat menggunakan software alternatif selain SPSS, seperti software PSPP, agar dapat menambah ilmu pengetahuan.

\section{Daftar Pustaka}

[1] Ahadzie, D. K. et al., 2008. Critical success criteria for mass house building projects in developing countries. International Journal of Project Management, Vol. 26, pp. 675-687.

[2] Arikunto, S., 2006. Prosedur Penelitian Suatu Pendekatan Praktik. Jakarta: Rineka Cipta.

[3] Cleland, D and Gareis, R., 2006. Global Project Management Handbok: Planning, Organizing, and Controlling International Projects, McGrawHill, New York.

[4] Cohen, et al., 2007. Metode Penelitian dalam Pendidikan. New York. Routledge.

[5] Ferdinand, A., 2006. Metode Penelitian
Manajemen. Semarang: Universitas Diponegoro.

[6] Ghozali, Imam dan Chariri. Anis., 2007. Teori Akuntonsi, Badan Penerbit Universitas Diponegoro Semarang.

[7] Hughes Et Al., 2004. Evaluasi Pelaksanaan Proyek Dengan Metode CPM: Universitas Indonesia.

[8] Kerzner., 2000. Project Management A System Approach to Planning, Schedulling, and Controlling, Seventh Edition, Singapore.

[9] Pujihastuti, I., 2010. Prinsip Penulisan Kuesioner Penelitian. CEFARS: Jurnal Agribisnis dan Pengembangan Wilayah. Vol. 2 No. 1.

[10] Riduwan, dan Sunarto., 2014. Pengantar Statistika untuk Penelitian Pendidikan, Sosial, Ekonomi, Komunikasi dan Bisnis. Bandung: Alfabeta

[11] Santoso., 2002. Statistik dengan SPSS. Elex Media Komputindo, Jakarta.

[12] Sugiyono., 2004. Metode Penelitian. Alfabeta : Bandung.

[13] Sudjana., 2005. Metode Statistika, Yogyakarta : Tarsito.

[14] Sugiyono., 2011. Metode Penelitian Kuantitatif Administratif, Bandung: Alfabeta.

[15] Sugiyono., 2014. Metode Penelitian Pendidikan Pendekatan Kuantitatif, Kualitatif dan R\&D, Bandung: Alfabeta.

[16] Sugiyono., 2015. Statistik Nonparametris untuk Penelitian, Bandung: Alfabeta.

[17] Yamin., 2013. Strategi dan Metode dalam Model pembelajaran Referensi (GP Press Group).

[18] Yuniarti, Eti., 2007. Analisis Pengungkapan Informasi Tanggung Jawab Sosial pada Sektor Perbankan di Indonesia. Tesis Program Pascasarjana. Universitas Diponegoro Semarang. 